\title{
INVESTIGATION ON DATA PROCESSING METHOD IN MULTI ANTENNA GPS SYSTEM DESIGNED FOR LANDSLIDE
}

\author{
Yuan Debao, Huang Lei, Yu Shiwei, Cao He, Liu Qiang
}

Original scientific paper

The global positioning system (GPS) is a satellite navigation system in the middle distance circular orbit. It can provide accurate positioning, speed testing, and high precision time standard in most parts of the earth's surface. Position can be quickly determined with only 3 satellites, but if want more accurate location, more satellites should be coupled. The conventional GPS monitoring method for deformation is that the GPS receiver is installed in each monitoring point. When there are many monitoring points, cost of the monitoring system will be quite high. In order to solve this problem, multi antenna GPS monitoring system has been proposed. Multiple antennas are connected to a receiver according to an additional GPS signal switch. So the data obtained in the system will be much larger than by the conventional GPS system. How to effectively process the large amount of data is a difficult problem. In this paper, the main content is to study the data processing method for a multi antenna GPS. Data compression method in a multi antenna GPS system with a high sampling rate is investigated. Data effective degree is used in the method to extract useful information. GPS data is coded by multi coding methods. According to the verification, the results show that the method is valid, and it can be used in the GPS data compression.

Keywords: code method; data compression; deformation; multi antenna GPS system; side slope

Analiza metode obrade podataka GPS sustava s više antena konstruiranog za klizišta

Izvorni znanstveni članak Globalni pozicionirajući sustav (GPS) je satelitski navigacijski sustav u kružnoj putanji srednje udaljenosti. Osigurava točno pozicioniranje, ispitivanje brzine i vrlo precizno vrijeme u većini dijelova zemljine površine. Položaj je moguće brzo odrediti sa samo 3 satelita, ali ako želimo točniju lokaciju, potrebno je spojiti više satelita. Uobičajena GPS metoda praćenja deformacija sastoji se u postavljanju GPS prijemnika u svakoj kontrolnoj točki. Kad ima mnogo kontrolnih točki, trošak kontrolnog sustava bit će također prilično visok. Za rješavanje ovog problema predlaže se GPS kontrolni sustav s više antena. Višestruke antene su povezane s prijemnikom preko dodatnog prekidača GPS signala. Tako će podaci prikupljeni u sustav biti mnogo veći nego pomoću uobičajenog GPS sustava. Veliki je problem kako učinkovito obraditi veliku količinu podataka. Bit je ovoga rada proučiti metodu obrade podataka za GPS s više antena. Istražuje se metoda sabijanja podataka u GPS sustavu s više antena za brzo uzimanje uzoraka. U metodi se koristi učinkovita količina podataka za dobivanje korisnih informacija. GPS podaci se kodiraju višestrukim metodama kodiranja. Provjera rezultata pokazala je valjanost metode za komprimiranje GPS podataka

Ključne riječi: deformacija; GPS sustav s više antena; metoda kodiranja; odron; sabijanje (komprimiranje) podataka

\section{Introduction}

The global positioning system (GPS) is a satellite navigation system in the middle distance circular orbit, which is researched and maintained by America department of defense. It can provide accurate positioning, speed testing, and high precision time standard in most parts of the earth's surface. It also can meet the need for a precise determination of the three-dimensional position [1-2], three-dimensional motion [3-4] and time. This system consists of 24 GPS satellites in space, one ground control station, three data injection stations and 5 monitor stations. Besides, there is also a user's receiver. Position and elevation of the user can be quickly determined with only 3 satellites in the system. The more satellites can be coupled, the more accurate decoding of the location.

The GPS system has the following advantages: the use of low frequency signal, and signal penetration remains fairly even if the bad weather appears; global coverage has been obtained; high precision for the three dimension speed and timing [5-8]; fast, time-saving, high efficiency; wide application, multi-function; location determination when moving; different from the double star positioning system, receiver does not need to send any signal in the process.

All kinds of error of GPS positioning in the process can be divided into three categories: errors, satellite related error related to signal propagation and error associated with the receiver. The effects of these errors on GPS positioning of each are not identical, and the size of the error and the satellite position, to be fixed position, the receiver equipment, observation time, the atmospheric environment and geographical environment and other factors. In view of the different error has the different analysis and processing method [9-13].

GPS was initially used to provide more accurate positioning, tracking marching soldiers and their equipment in the field, navigation for naval ships, navigation for missile flight, and navigation for military aircraft [14-16]. In recent years, GPS is also widely used in civilian applications, such as dynamic parameters measurement of the lands [17-18], marine geodesy and surveying [19]; earth plate monitoring and earth deformation monitoring [20], engineering measurement, aerospace photography mapping, tracking vehicle location, mapping the terrain deformation, and so on [21-22].

The conventional GPS monitoring method for deformation is that the GPS receiver is installed in each monitoring point. When there are many monitoring points, cost of the monitoring system will be quite high. Aiming at solving this problem, multi antenna GPS monitoring system has been proposed [23-26]. Based on the existing GPS receiver structure, multiple antennas are connected to a receiver according to an additional GPS signal switch. At the same time, a receiver can be connected to more than one antenna according to a multi antennas conversion switch. Deformation law of deformable body can also be obtained by processing the GPS data. If this method is adopted, the cost of the monitoring system can be decreased by reducing the number of the receivers, and 
the application range will be greatly expanded. There are many applications in the field of construction and public facilities, such as in the dam deformation, landslide slope, and dynamic deformation of the bridge.

However, the multi antenna GPS also has its disadvantages [27]. Due to the only one receiver, processing speed and efficiency will be greatly reduced, especially in the large scale antenna arrays. This is a particular disadvantage. Therefore, it is needed to increase processing capacity and processing speed in data processing. As everyone knows, processing efficiency improving depends on the processor and processing algorithm. When the processor is determined, processing method will be very important.

In fact, if the processor is determined according to the science and technology, then, the processing performance will increase by some extent. Much more attention will be paid to investigation on the processing method [28-29].

The data compression method is so important, and much more attention should be paid to studying it. Although there are many methods proposed for the GPS data compression, there is still not enough of them for the multi antenna GPS data. In this paper, the main aim is to study the data processing method for a multi antenna GPS Data compression method in a multi antenna GPS system with a high sampling rate is investigated, and a new compression method has been developed. The remainder of the paper is shown as the following: The main process method is shown in Section 2; a data collection system has been designed in Section 3; data compression method is described in Section 4, which is divided into two kinds; the verification is shown in Section 5; and the Section 6 gives the conclusion.

\section{The main processing method}

The multi antenna GPS system is shown in Fig. 1. Many data compression methods have been published in the past years. Data compression algorithm can be classified into lossless and lossy compression. The lossy compression means that the original data cannot be obtained completely just according to the compressed data, and data recovered is an approximation to distortion degree. The coding compression algorithm is usually used in image communication and video entertainment equipment, and compression rate is high. The lossy compression has been widely applied. Lossless compression algorithm means that the original data can be recovered completely by the compressed data without the data distortion. The compression ratio is relatively smaller than that of the lossy compression algorithm. Lossless compression algorithm is widely used in text data, procedure and all kinds of special applications.

Commonly used lossless data compression algorithms include variety of Huffman coding algorithms, arithmetic coding algorithm, dictionary based compression algorithm and text data compression algorithm, and so on. GPS positioning data belong to the test data. Due to the characteristics of GPS positioning data, the wavelet algorithm is also adopted to process the GPS data.

Application of wavelet analysis is able to compress the signal, because the comparison rules signal is composed of a low frequency coefficient for a low data amount and some coefficients for high frequency layers. Here, there is a demand for the selection of low frequency coefficient: it requires low frequency coefficients selected in a proper decomposition layer. To compress the onedimensional signal, the basic process is the analysis of input signal by wavelet. The decomposed high frequency wavelet data will be processed with quantization. After the process, both high-frequency and low-frequency signal will be reconstructed, and the reconstructed signal will be output.

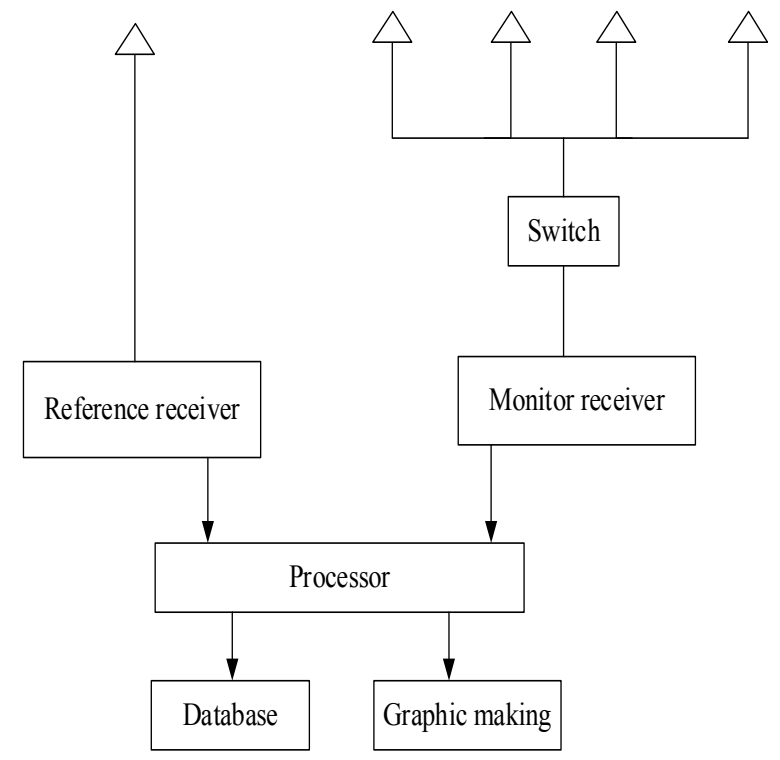

Figure1 Multi antenna GPS system

\section{System design}

Key technologies of multi antenna GPS monitoring system are also involved in transmission of the GPS signal. Because the monitoring area is usually wide, the distance between the measured points may be quite far. Therefore, GPS system with multi antenna will inevitably encounter the problem of the long distance transmission of signal with excessive attenuation. According to the conclusion of experiments, when the transmission distance reaches $30 \div 60 \mathrm{~m}$, signal loss will be quite large, and even the signal can be completely lost. To solve this problem, on one hand, the performance of the transmission medium should be improved, such as the using of low loss cable or fiber optic transmission; on the other hand, appropriate signal should be enhanced, and development of the GPS signal with low noise amplifier should be proposed and applied.

As we know, the deformation of the side slope is quite small at first and quite fast when the landslide happens. So in the data collection system, we adopted the time varied mechanism at different periods of the landslide. At the beginning, the collection period will be long, the data sets obtained for the second time will be compared with those obtained at the first time. If the position between the two data sets is of big difference, for example the difference is $5 \%$, the collection period will be shortened. The shortened percentage has a direct ratio to the difference of the data sets collected in two adjacent periods. 


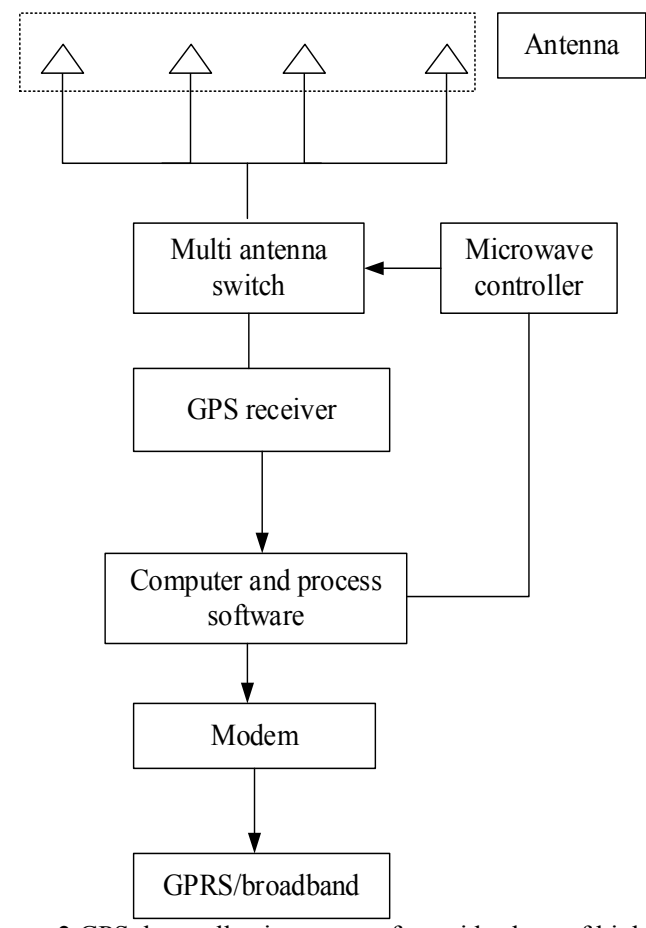

Figure 2 GPS data collection system for a side slope of highway

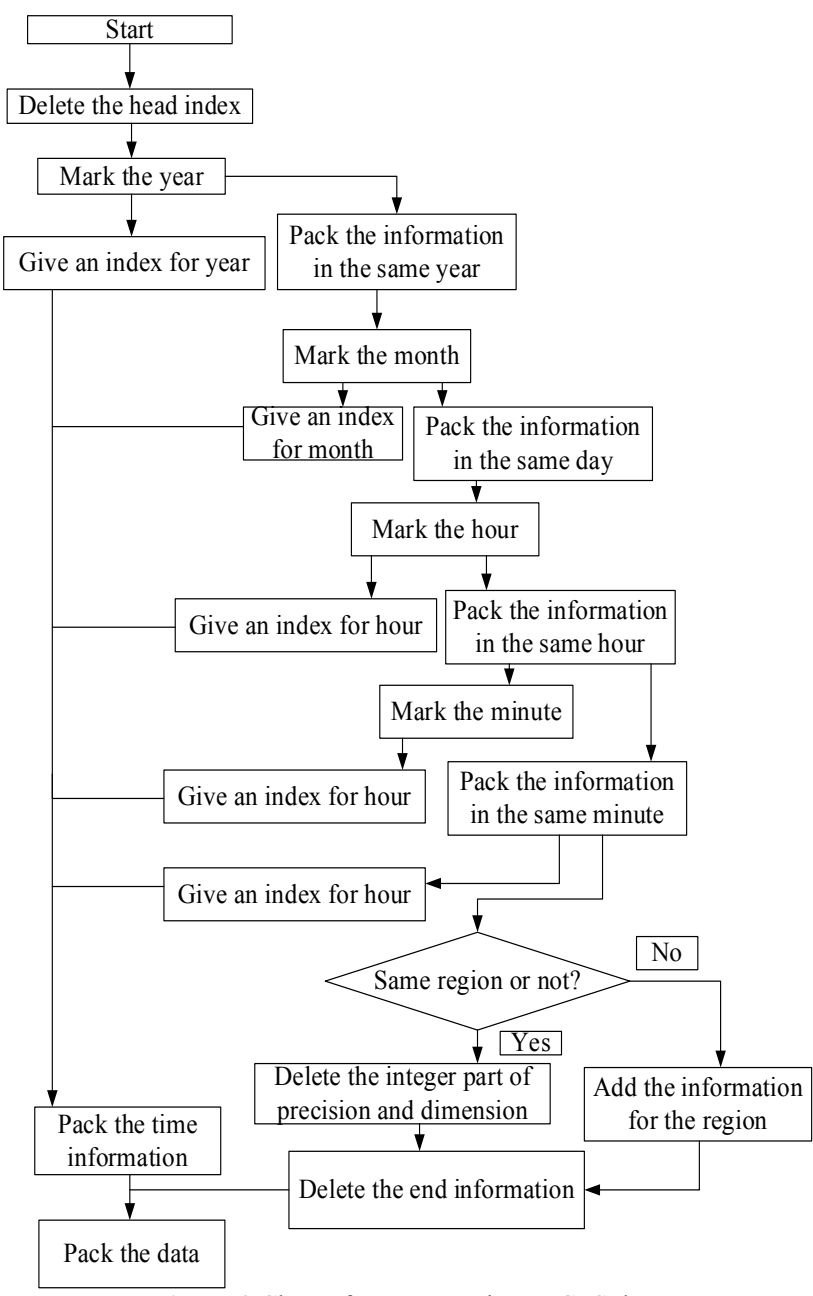

Figure 3 Chart of pre-processing to GPS data

The data compression is classified into two kinds. Small amount data compress model is for the data collected at the initial period, the main characteristic is the small data quantity; the other kind is the huge amount data compress model for the data collected at the period when the landslide happened, the data quantity is huge.

\section{Data compression method 4.1 Data compression model for small amount data}

GPS data outputs in binary throttle mode, and the data consist of a number of sentences. In order to meet the demand of accurate calculation for long string n GPS data, $\mathrm{BCD}$ code is selected for the compression.

Compared to the conventional floating-point notation, compressed BCD code can save the numerical accuracy and reduce the time consumption in floating-point arithmetic in the computer. The order is as follows: the acquisition time, latitude, longitude, speed, direction and orientation. Multi-byte variable adopts the mechanism of high byte in the front and low byte in the post.

According to observed output format of the GPS data, a lot of redundant data have been found. In order to facilitate the subsequent compression, we should pretreat the signal with difference, as shown in Fig. 3.

The Hoffman Code is adopted as the basis, preprocessed data will be dealt with lossless compression. At the same time, information entropy is used as the index to test the amount of information. This is to say that the compressed digital rate will not be less than the entropy of the data. The pretreated data are directly compressed by Huffman algorithm, and the probability of occurrence of each character is shown in Fig. 2.

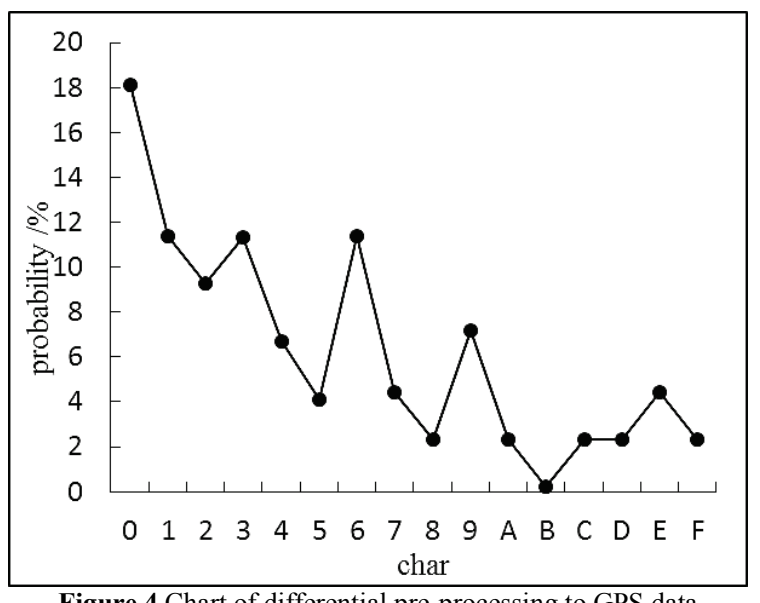

Figure 4 Chart of differential pre-processing to GPS data

Then Hoffman code is used to encode the data after the pre-processing, the data compression code is shown in Tab. 1.

Table1 Huffman code

\begin{tabular}{|c|c|c|c|}
\hline Code & Huffman code & Code & Huffman code \\
\hline 0 & 011 & 8 & 00100 \\
\hline 1 & 000 & 9 & 0011 \\
\hline 2 & 100 & A & 010100 \\
\hline 3 & 110 & B & 0010100 \\
\hline 4 & 0100 & C & 010101 \\
\hline 5 & 1010 & D & 001011 \\
\hline 6 & 111 & E & 01011 \\
\hline 7 & 1011 & F & 0010101 \\
\hline
\end{tabular}

Calculate the information entropy: 


$$
H(x)=-\sum_{i=0}^{15} P\left(x_{i}\right) \log _{2} P\left(x_{i}\right)=3,64 \text {. }
$$

And the mean code length is:

$$
\bar{L}=\sum_{i=0}^{15} P_{i} n_{i}=3,62
$$

Although lossy compression cannot completely recover the original data, the loss of data is of small influence in understanding the original information. Besides, it can also get higher compression ratio. Therefore, proper lossless compression can be used in the compression process to further enhance the compression ratio according to the lossless compression after pretreatment. With high compression ratio, processing speed and transmission quality of GPS data can be greatly improved. Through experiment and analysis, a certain time delay appears from the receiving and analyzing the data to the data processing, and the delay time interval is often stable. Therefore, a fixed time interval can be chosen to convert the common time format.

In the following, we will take GPS data compression as an example. For large amount of GPS data, the processing referred to huge computation for the compression, recovering, position calculation, speed calculation, and map matching. So it is important to ensure the time consumption in the compression process. If the compression time is long, the time delay will be long, and this is harmful for the real time monitoring. Therefore, when the GPS data are in small amount, they can be deeply compressed. Although the recovery time is longer, it is allowed. When the GPS data quantity are quite large, the compression depth should be considered due to disadvantages of the long compression time and recovery time.

The transfer algorithm can be described as follows:

(1) Mark the position $S_{i}$ as point position $i$ in the landslide; $n$ is the time interval; $v_{i}$ is the real time speed; $T_{m}$ and $T_{n}$ are the starting and ending time in one period, respectively; $R_{1}$ is set for $t$, and $R_{2}$ is set for $t_{m}$ and $t_{n}$. Where, $t \in R_{1} ; t_{m}, t_{n} \in R_{2}$, and $t_{m}<t_{n}$.

(2) In order to facilitate data processing as well as for greater compression ratio, one day is divided into numbers of time interval. At the initial time, the time interval is $10 \mathrm{~min}$. Then all the day can be divided into 144 time intervals. There will be 6 time periods in an hour And the time can be calculated by Eq. (3):

$t_{m}=H_{t} \times 6+\frac{M_{t}}{10}$

The monitor will be working all the day, and the start

$$
\begin{aligned}
& t_{m}=H_{t} \times 0+\frac{0}{10}=0 \\
& t_{m}=23 \times 6+\frac{60}{10}=144 .
\end{aligned}
$$

\subsection{Data compression model for large amount data}

The method described above is for the initial period with small amount data. When the side slope is moving quickly, the relationship between compression time and recovery time should be balanced to get the highest performance.

For the large amount data, the time period will be set shorter, some time and positon information will not be compressed, and the calculating method has no change.

\subsection{Assessment for the compression performance}

(1) The coding efficiency

The coding efficiency can be defined as the ratio of the information entropy and code length.

$\eta=\frac{H(x)}{L} \times 100 \%$

The compression work is mainly on 3 parts of GPS data: data preprocessing to cut the redundancy information, the Hoffman code to realize the lossless compression, and transformation of data types to realize the loss compression. Therefore, the data compression ratio will be defined as the following:

$\eta=\left[\frac{C R}{L}+\frac{H E}{L}+\frac{L C}{L}\right] \times 100 \%$,

where, $L$ is the code length; $C R$ represents the data preprocessing part; $H E$ represents the Huffman code part; and $L C$ means the lossy compression.

(2) The compression ratio

The compression ratio is defined as the ratio of compression length to total code length.

$C=\frac{L-l}{L} \times 100 \%$.

(3) The effective degree

$E=1-C$

It means the effective information in all the data collected, and this index will be used in the compression

\begin{tabular}{|c|c|c|c|c|}
\hline $\begin{array}{c}\text { Original } \\
\text { data } \\
\text { storage }\end{array}$ & $\begin{array}{c}\text { Pre- } \\
\text { processing }\end{array}$ & $\begin{array}{l}\text { Huffman } \\
\text { code }\end{array}$ & $\begin{array}{c}\text { Style } \\
\text { conversion }\end{array}$ & $\begin{array}{c}\text { Total } \\
\text { compression } \\
\text { ratio }\end{array}$ \\
\hline 395 & $51,41 \%$ & 8,49 & $13,86 \%$ & 61,69 \\
\hline
\end{tabular}
algorithm.

Tabs. 2 and 3 show the initial compression results for each step and the total compression results.

\begin{tabular}{|c|c|c|c|c|}
\multicolumn{5}{c}{ Table 3 The compression efficiency } \\
\hline $\begin{array}{c}\text { Original } \\
\text { data } \\
\text { storage }\end{array}$ & $\begin{array}{c}\text { Pre- } \\
\text { processing }\end{array}$ & $\begin{array}{c}\text { Huffman } \\
\text { code }\end{array}$ & $\begin{array}{c}\text { Style } \\
\text { conversion }\end{array}$ & $\begin{array}{c}\text { Total } \\
\text { compression } \\
\text { ratio }\end{array}$ \\
\hline 395 & $49,12 \%$ & 8,18 & $11,83 \%$ & 58,70 \\
\hline
\end{tabular}




\section{Experimental test}

\subsection{Small amount data at the initial period}

Dynamic GPS data will change with the time varying. We select a small rectangle area to verify the new method. We have collected data for 7 periods, and the data is processed with new method.

The test results show that, redundancy removal data accounted is about $51,4 \%$, Hoffman coding compression rate is about $8,5 \%$, while the style conversion of the compression ratio is around $13,8 \%$. The total amount of compression was maintained at about $61,7 \%$.

Table 4 Compression rate after each step for 7 periods

\begin{tabular}{|c|c|c|}
\hline period & Original file & Total compression ratio \\
\hline 1 & 83756 & $61.69 \%$ \\
\hline 2 & 83523 & $61.68 \%$ \\
\hline 3 & 82939 & $61.64 \%$ \\
\hline 4 & 83232 & $61.67 \%$ \\
\hline 5 & 83575 & $61.71 \%$ \\
\hline 6 & 83347 & $61.68 \%$ \\
\hline 7 & 83802 & $61.69 \%$ \\
\hline
\end{tabular}

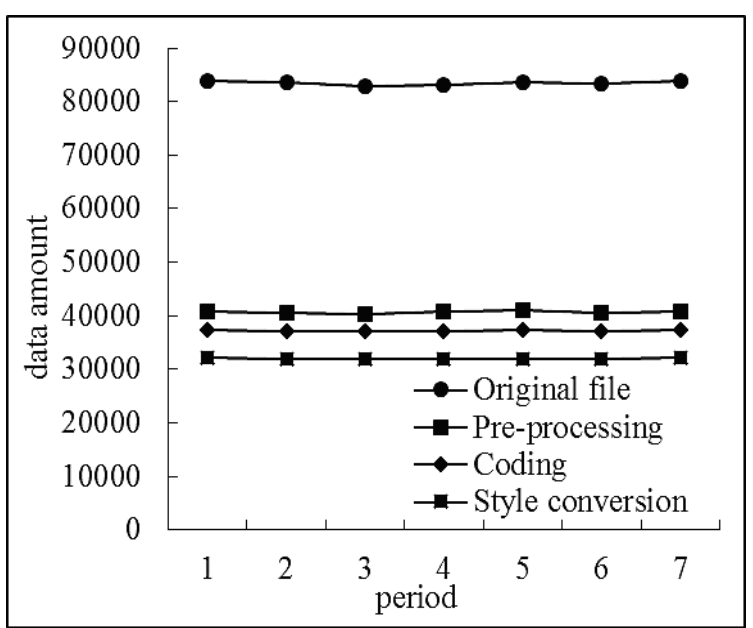

Figure 5 Data compressed after each step for 7 periods (unit:byte)

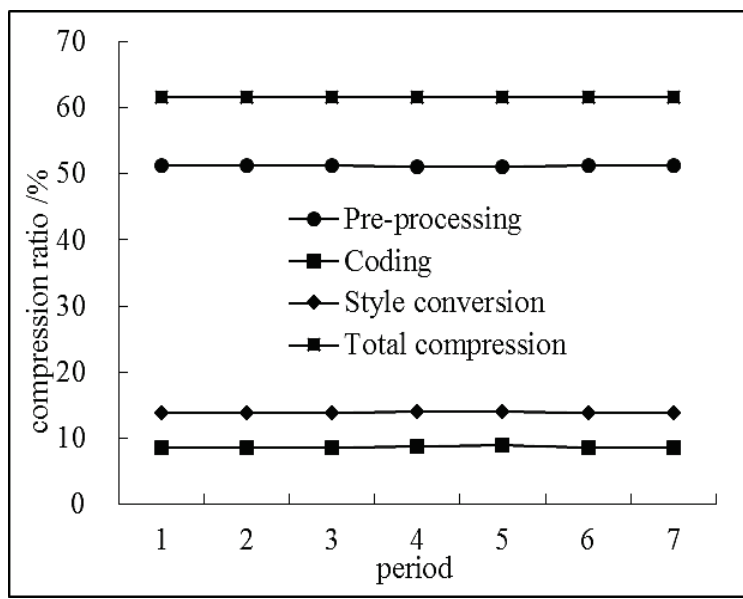

Figure 6 Data compressed ratio for each step for 7 periods

Fig. 5 and Fig. 6 show the data compression amount and compress ratio of the data. Tab. 5 shows the comparison ratio by different compression methods. It can be shown that the new compression method can improve the compression ratio.

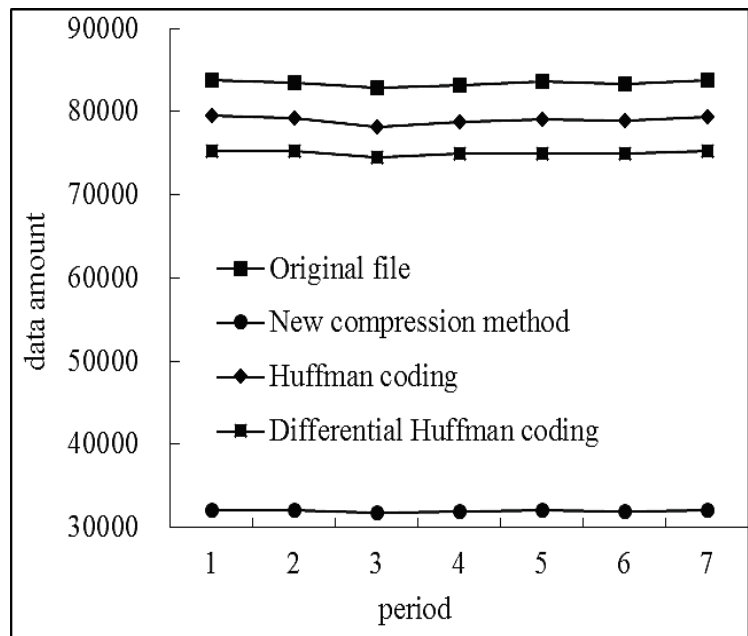

Figure7 Compression amount with different methods (unit: byte)

According to the test results from the experiment, least square method is used to fit the trend of compression amount and compression ratio, as shown in Fig. 7 and Fig. 8 . It can be found that the compression ratio will increase with the increasing of the data amount.

Table 5 Comparison with other compression methods (unit: byte)

\begin{tabular}{|c|c|c|c|c|c|c|c|}
\hline \multirow{2}{*}{ Period } & \multirow{2}{*}{$\begin{array}{c}\text { Original file } \\
\text { amount }\end{array}$} & \multicolumn{2}{|c|}{ New compression method } & \multicolumn{2}{|c|}{ Huffman coding } & \multicolumn{2}{|c|}{ Differential Huffman coding } \\
\hline & & amount & Ratio \% & amount & Ratio \% & amount & Ratio \% \\
\hline 1 & 83756 & 32084 & 61,69 & 79568 & 5,0 & 75297 & 10,1 \\
\hline 2 & 83523 & 32000 & 61,68 & 79180 & 5,2 & 75338 & 9,8 \\
\hline 3 & 82939 & 31811 & 61,64 & 78129 & 5,8 & 74479 & 10,2 \\
\hline 4 & 83232 & 31896 & 61,69 & 78737 & 5,4 & 75000 & 9,89 \\
\hline 5 & 83575 & 31999 & 61,71 & 79146 & 5,3 & 74967 & 10,3 \\
\hline 6 & 83347 & 31937 & 61,68 & 78930 & 5,3 & 74929 & 10,1 \\
\hline 7 & 83802 & 32101 & 61,69 & 79444 & 5,2 & 75254 & 10,2 \\
\hline
\end{tabular}

\subsection{Large amount data at the latter period}

The method described above is for the initial period with small amount data. When the side slope is moving quickly, the relationship between compression time and recovery time should be balanced to get the highest performance. In the paper, when the data amount is big enough, information will be compressed selectively. This is to balance the compression time, recovery time, and the motion of the landslide. If the compression and recovery time is short, the motion of the landslide will be processed quickly. So, in this part, if the speed is fast, the 
compression will not proceed for a minute or even hour. Due to the landslide is not controlled; here we just increased the sampling frequency artificially.

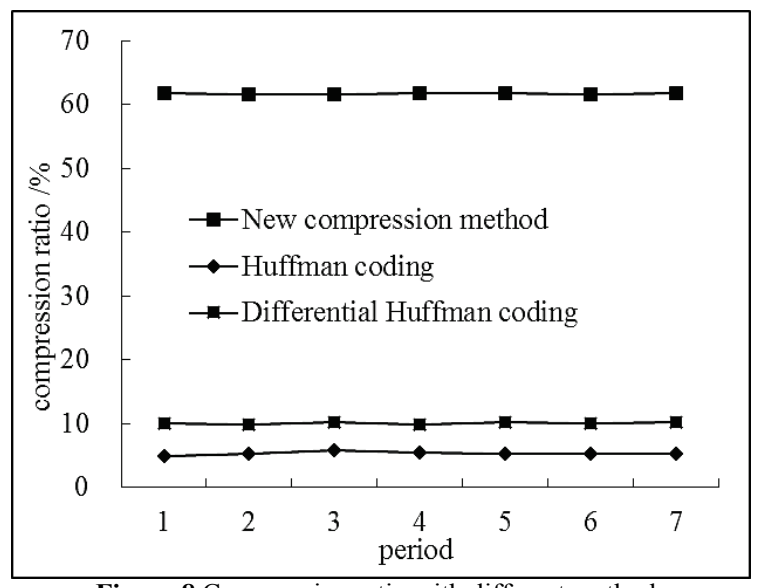

Figure 8 Compression ratio with different methods

Dynamic GPS data will change with the time varying. We also have collected data for 7 periods, and the data are processed with the new method.

Table 6 Compression rate after each step for 7 periods (unit: byte)

\begin{tabular}{|c|c|c|}
\hline Period & Original file & Total compression ratio \% \\
\hline 1 & 382756 & 58,71 \\
\hline 2 & 383523 & 58,74 \\
\hline 3 & 384939 & 58,73 \\
\hline 4 & 388232 & 58,80 \\
\hline 5 & 382575 & 58,74 \\
\hline 6 & 383802 & 58,78 \\
\hline 7 & 383890 & 58,74 \\
\hline
\end{tabular}

The test results show that redundancy removal data accounted is about $49 \%$, Hoffman coding compression rate is about $8,18 \%$, while the style conversion of the compression ratio is around $11,8 \%$. The total amount of compression was maintained at about 58,7 \% .

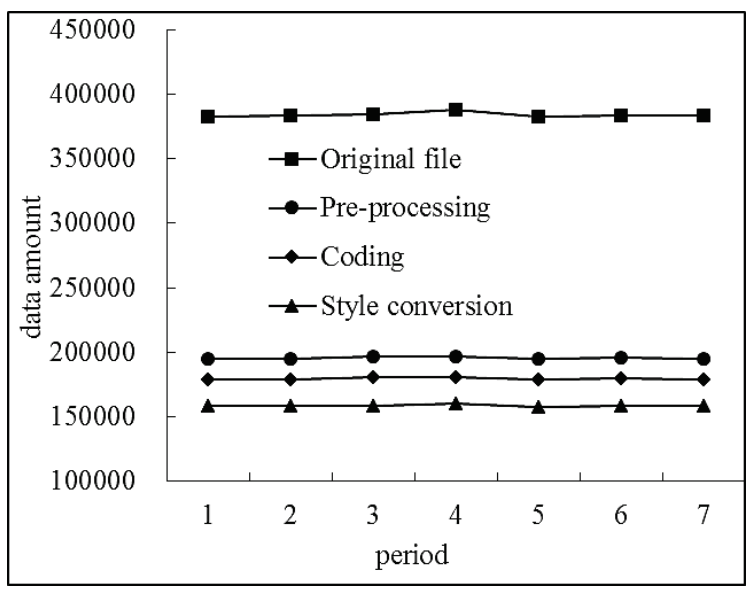

Figure 9 Data compressed after each step for 7 periods (unit: byte)

Figs. 9 and 10 show the data compression amount and compression ratio of the data. Tab. 7 shows the comparison ratio by different compression methods. It can be shown that the new compression method can improve the compression ratio.

According to the test results from the experiment, least square method is used to fit the trend of compression amount and compression ratio, as shown in Figs. 11 and 12. It has the same principle as the compression for small amount data.

Table 7 Comparison with other compression methods (unit: byte)

\begin{tabular}{|c|c|c|c|c|c|c|c|}
\hline \multirow[t]{2}{*}{ Period } & \multirow[t]{2}{*}{ Original file } & \multicolumn{2}{|c|}{ New compression method } & \multicolumn{2}{|c|}{ Huffman coding } & \multirow{2}{*}{$\begin{array}{c}\text { Differential } \\
\text { Huffman coding }\end{array}$} & \multirow{2}{*}{$\begin{array}{c}\begin{array}{c}\text { Compression } \\
\text { ratio }\end{array} \\
\text { Ratio } \%\end{array}$} \\
\hline & & Amount & Ratio \% & Amount & Ratio \% & & \\
\hline 1 & 382756 & 158025 & 58.71 & 364384 & 4.8 & 346011 & 9.6 \\
\hline 2 & 383523 & 158240 & 58.74 & 365497 & 4.7 & 347088 & 9.5 \\
\hline 3 & 384939 & 158860 & 58.73 & 366462 & 4.8 & 347215 & 9.8 \\
\hline 4 & 388232 & 159959 & 58.80 & 370373 & 4.6 & 351738 & 9.4 \\
\hline 5 & 382575 & 157855 & 58.74 & 364594 & 4.7 & 345848 & 9.6 \\
\hline 6 & 383802 & 158220 & 58.78 & 366531 & 4.5 & 347341 & 9.5 \\
\hline 7 & 383890 & 158381 & 58.74 & 365847 & 4.7 & 347037 & 9.6 \\
\hline
\end{tabular}

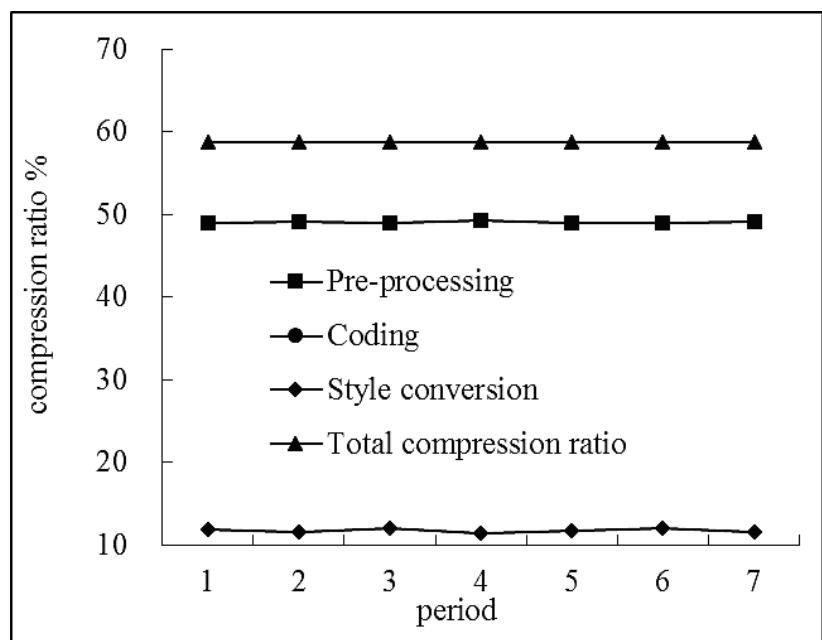

Figure 10 Data compressed ratio for each step for 7 periods

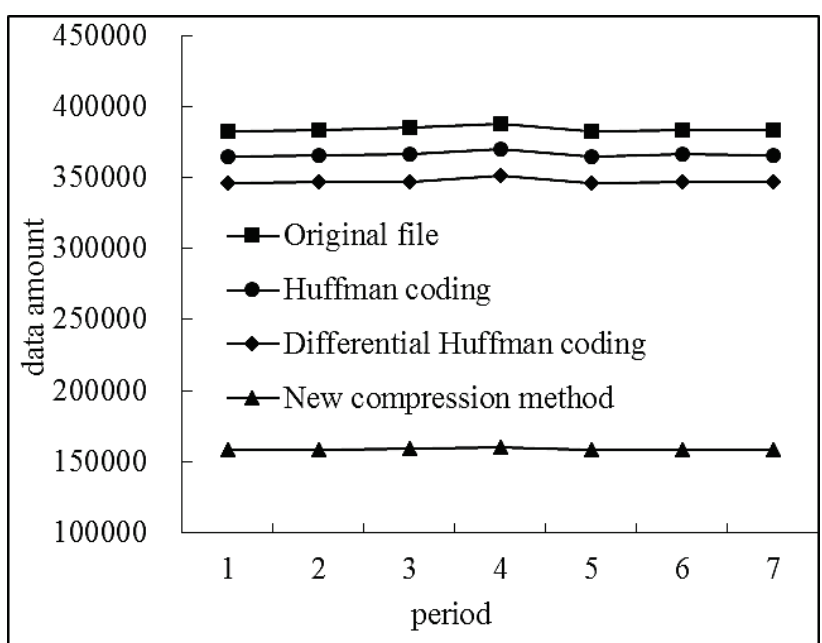

Figure11 Compression amount with different methods (unit: byte) 


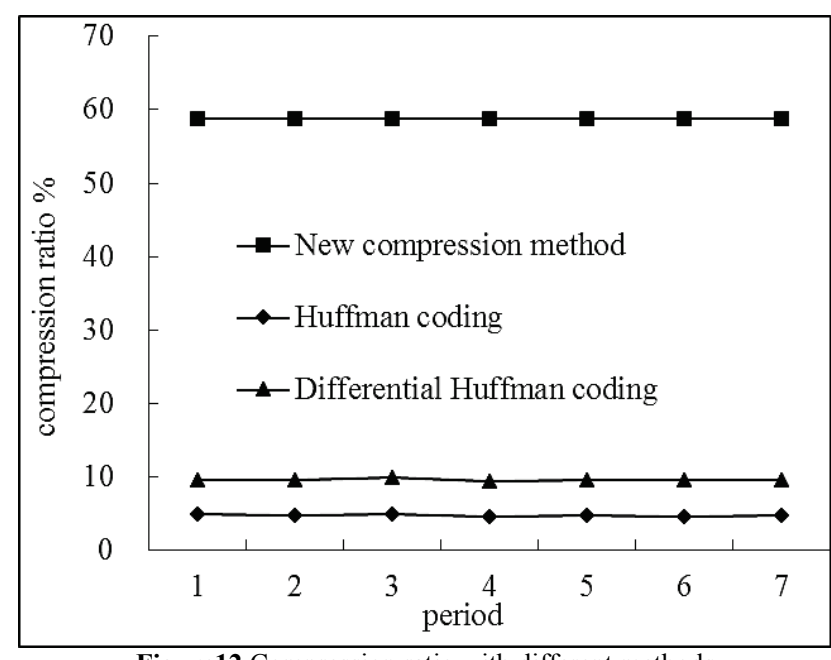

Figure12 Compression ratio with different methods

\section{Conclusion}

The GPS is researched and maintained by America department of defense, which can provide accurate positioning, speed testing, and high precision time standard in most parts of the earth's surface. The conventional GPS monitoring method for deformation is that the GPS receiver is installed in each monitoring point. When there are many monitoring points, cost of the monitoring system will be quite high. Multi antenna GPS monitoring system can solve the problem properly. Therefore it is developed quickly after being proposed. Multiple antennas GPS can realize the purpose by setting a switch. Due to the multi antennas, the data amount in the multiple antennas system is also large, and it is quite important to investigate the compression method to improve the transferring efficiency.

In this paper, we design a system to collect data and transfer data for a side slope of highway. Due to the deformation of the landslide, two modes have been designed in the system. So in the data collection system, time varied mechanism at different period for the landslide deformation is adopted.

According to the experimental test, we get some conclusions:

(1) In the initial periods, the data quantity is less, the redundancy removal data accounted is about $51,4 \%$, Hoffman coding compression rate is about 8,5\%, while the style conversion of the compression ratio is around $13,8 \%$. The total amount of compression was maintained at about $61,7 \%$. Compared with other compression methods, the new compression method can improve the compression ratio. Compression ratio will increase with the increasing of the data amount.

(2) In the latter periods, redundancy removal data accounted is about $49 \%$, Hoffman coding compression rate is about $8,18 \%$, while the style conversion of the compression ratio is around $11,8 \%$. The total amount of compression was maintained at about 58,7 \%. The conclusion is the same with the results obtained in the initial periods, the new compression method can improve the compression ratio.

According to the verification results, the method is proven to be valid and it can be used in the multi antennas GPS.

\section{$7 \quad$ References}

[1] Rao, G.; Bhushana, S.; Rajkumar, G. Ionospheric delay estimation for improving the Global Positioning System position accuracy. // IETE Journal of Research. 54, 1(2008), pp. 23-29. DOI: 10.1080/03772063.2008.10876178

[2] Norikazu, S.; Shinichiro, N.; Tomohiro, M. ISRM suggested method for monitoring rock displacements using the global positioning system (GPS). // Rock Mechanics and Rock Engineering. 47, 1(2014), pp. 313-328. DOI: 10.1007/s00603-013-0521-5

[3] Wang, B.; Deng, Z.; Wang, S.; Fu, M. A motion-based integer ambiguity resolution method for attitude determination using the global positioning system (GPS). // Measurement Science and Technology. 21, 6(2010). DOI: 10.1088/0957-0233/21/6/065102

[4] Zhang Xinggang; Jin Shuanggen. Uncertainties and effects on geocenter motion estimates from global GPS observations. // Advances in Space Research. 54, 1(2014), pp. 59-71. DOI: 10.1016/j.asr.2014.03.021

[5] Shepard, D. P.; Humphreys, T. E. High-precision globallyreferenced position and attitude via a fusion of visual SLAM, carrier-phase-based GPS, and inertial measurements. Record - IEEE PLANS, Position Location and Navigation Symposium, (2014), pp. 1309-1328. DOl: 10.1109/plans.2014.6851506

[6] Jia Dong-Yao; Ai Yan-Ke. High-precision GPS matching algorithm based on two-circle method regional division. // Journal of the China Railway Society. 35, 10(2013), pp. 6772.

[7] Chen Linzhouting; Fang Jiancheng. A hybrid prediction method for bridging GPS outages in high-precision POS application. // IEEE Transactions on Instrumentation and Measurement. 63, 6(2014), pp. 1656-1665. DOI: 10.1109/TIM.2013.2292277

[8] Li Xingxing; Ge Maorong; Zhang Xiaohong; Zhang Yong; Guo Bofeng; Wang Rongjiang; Klotz Jürgen; Wickert Jens. Real-time high-rate co-seismic displacement from ambiguity-fixed precise point positioning: Application to earthquake early warning. // Geophysical Research Letters. 40, 2(2013), pp. 295-300. DOI: 10.1002/grl.50138

[9] Azarbad, M. R.; Mosavi, M. R. A new method to mitigate multipath error in single-frequency GPS receiver with wavelet transform. // GPS Solutions. 18, 2(2014), pp. 189198. DOI: 10.1007/s10291-013-0320-1

[10] Paz, J. P. Z.; Shmaliy, Y. Predictive estimation of the time interval error signals GPS SynPaQ III based with holdover problems. // IEEE Latin America Transactions. 11, 2(2013), pp. 698-705. DOI: 10.1109/TLA.2013.6533957

[11] Iqbal, U.; Georgy, J.; Korenberg, M. J.; Noureldin, A. Modeling residual errors of GPS pseudoranges by augmenting Kalman filter with PCI for tightly-coupled RISS/GPS integration. // $23^{\text {rd }}$ International Technical Meeting of the Satellite Division of the Institute of Navigation 2010, ION GNSS 2010. 3, (2010), pp. 22712279 .

[12] Rife, J.; Pervan, B. Overbounding revisited: Discrete errordistribution modeling for safety-critical GPS navigation. // IEEE Transactions on Aerospace and Electronic Systems, 48, 2(2012), pp. 1537-1551. DOl: 10.1109/TAES.2012.6178077

[13] Bhatti, U. I.; Ochieng, W. Y.; Feng, S. Performance of rate detector algorithms for an integrated GPS/INS system in the presence of slowly growing error. // GPS Solutions. 16, 3(2012), pp. 293-301. DOI: 10.1007/s10291-011-0231-y

[14] Psiaki, M. L.; O'Hanlon, B. W.; Bhatti, J. A.; Shepard D. P.; Humphreys, T. E. GPS spoofing detection via dual-receiver correlation of military signals. // IEEE Transactions on Aerospace and Electronic Systems. 49, 4(2013), pp. 22502267. DOI: 10.1109/TAES.2013.6621814 
[15] Alexander, S. D. Interference-resistant vertically-guided approaches for military aircraft in civil airspace. $/ / 26^{\text {th }}$ International Technical Meeting of the Satellite Division of the Institute of Navigation, ION GNSS 2013. 3, (2013), pp. 2569-2576.

[16] Soghoyan, A.; Suleiman, A.; Akopian, D. A development and testing instrumentation for GPS software defined radio with fast FPGA prototyping support. // IEEE Transactions on Instrumentation and Measurement. 63, 8(2014), pp. 2001-2012. DOI: 10.1109/TIM.2014.2304352

[17] Santamaría-Gómez, A.; Gravelle, M.; Collilieux, X.; Guichard, M.; Míguez, B. M.; Tiphaneau, P.; Wöppelmann, G. Mitigating the effects of vertical land motion in tide gauge records using a state-of-the-art GPS velocity field. // Global and Planetary Change. 98-99(2012), pp. 6-17. DOl: 10.1016/j.gloplacha.2012.07.007

[18] Kierulf, H. P.; Plag, H.-P.; Bingley, R. M.; Teferle, N.; Demir, C.; Cingoz, A.; Yildiz, H.; Garate, J.; Davila, J. M.; Silva, C. G.; Zdunek, R.; Jaworski, L.; Martinez-Benjamin J. J.; Orus, R.; Aragon, A. Comparison of GPS analysis strategies for high-accuracy vertical land motion. // Physics and Chemistry of the Earth. 33, 3-4(2008), pp. 194-204. DOI: 10.1016/j.pce.2006.11.003

[19] Yuanfenghua, B. Estimating the range of marine radar with vertical atmospheric refractivity profiles from ground-based GPS. // 2011 International Conference on Electric Information and Control Engineering, ICEICE 2011 Proceedings. (2011), pp. 3241-3243.

[20] Zhang, Hao; Ji, Min; Shi, Xi; Zhou, Sheng-Liang. Application study on GPS positioning technology for gravity wharf deformation monitoring. // Applied Mechanics and Materials. 578-579, (2014), pp. 1079-1082. DOI: 10.4028/www.scientific.net/AMM.578-579.1079

[21] Li, Zishen; Sandra; De Bakker, Peter; Yuan, Hong; Zhong, Shiming. Mitigation of ionospheric delay in GPS/BDS single frequency PPP: Assessment and application. // Lecture Notes in Electrical Engineering, 304 LNEE. (Vol. 2) (2014), pp. 477-499.

[22] Chen, Gang; Cheng, Xingwen; Chen, Weitao; Li, Xianju; Chen, Liangbiao. GPS-based slope monitoring systems and their applications in transition mining from open-pit to underground. // International Journal of Mining and Mineral Engineering. 5, 2(2014), pp. 152-163. DOI: 10.1504/IJMME.2014.060219

[23] Lu, G.; Lachapelle, G.; Cannon, M. E.; Kielland, P. Attitude determination in a survey launch using multiantenna GPS technology. // Proceedings of the National Technical Meeting, Institute of Navigation, (1993), pp. 251260

[24] Yeh, T. K.; Hu, Y. S.; Liou, Y. A. Analysis of landslide monitoring using an e-GPS system and multi-antenna GPS technology. // IAHS-AISH Publication. 339, (2010), pp. 374-376.

[25] Wang, Jin-Song; Chen, Zheng-Yang; Liang, Guang-Hua. Study of real time monitoring system of highway steep slopes based on GPS with multi-antenna. // Rock and Soil Mechanics. 30, 5(2009), pp. 1532-1536.

[26] He, Zhi-Yong; Zhang, Jian-Jun. Study of bridge health monitoring scheme based on GPS multi-antenna technique. // Advanced Materials Research. 433-440, (2012), pp. 3400-3402.

[27] Hirokawa, Rui; Ebinuma, Takuji. A low-cost tightly coupled GPS/INS for small UAVs augmented with multiple GPS antennas. // Navigation, Journal of the Institute of Navigation. 56, 1(2009), pp. 35-44.

[28] Baffour, R. A. Collecting roadway cross slope data using multi-antenna-single receiver GPS configuration. // Proc. of the International Conference on Applications of Advanced Technologies in Transportation Engineering. (2002), pp. 354-361. DOI: $10.1061 / 40632(245) 45$
[29] Sun, Huangqi. Integration of a GPS multi-antenna system with a CCD camera for rapid GIS data acquisition. // Proceedings of ION GPS. 2, (1996), pp. 1457-1464.

\section{Authors' addresses}

\section{Yuan Debao}

College of Geoscience and Surveying Engineering, CUMTB, Beijing, China, 100083

E-mail: yuandb@cumtb.edu.cn

\section{Huang Lei}

College of Geoscience and Surveying Engineering, CUMTB, Beijing, China, 100083

\section{Yu Shiwei}

College of Geoscience and Surveying Engineering, CUMTB, Beijing, China, 100083

Cao He

College of Geoscience and Surveying Engineering, CUMTB, Beijing, China, 100083

\section{Liu Qiang}

College of Geoscience and Surveying Engineering, CUMTB, Beijing, China, 100083 